\section{Histórico do INPA}

O INSTITUTO NACIONAL DE PESQUISAS DA AMAZŌNIA foí criado pelo Decreto $n .^{\circ} 31.672$, de 29 de outubro de 1952 , nos termos dá Lei n. 1.310 , de 15 de janeiro de 1951, para substituir um organismo denominada HILÉlA AMAZÔNICA, cuja finalidade era a valorização da Amazônia Internacional, e em que estavam interessados todos os paises dessa região física-humana. Naturalmente essa organização não chegou a ter existência, pois a crítica nacional iniciou uma campanha de descrédito, no sentido de fazer valer o espírito de potencialidade do país. De inspiração da UNESCO, em 1947, foi instalada em Manaus em maio de 1948, não merecendo o apoio do Congresso Nacional. A finalidade precípua do INPA era e está sendo valorizar a Amazônia em todos os seus aspectos, explorando-a cientificamente, de acordo com o estabelecido na Carta de 1946 que promovia a incorporação da Amazônia.

O seu primeiro Regimento foi aprovado pelo Decreto $n .^{\circ} 35.133$, de 1 de março de 1954. O Presidente do Conselho Nacional de Pesciuisas designou os professores Drs. Olímpio Oliveira Ribeiro da Fonseca e Mário Ulisses Viana Dias para, sob a presidência do primeiro, "estudarem o plano de organização e o programa preliminar das atividades do Instituto". Por Portaria de 4 de junho de 1954 do Presidente do Conselho Nacional de Pesquisas foi o professor Olímpio da Fonseca designado em Comissão para o cargo de Diretor do Instituto Nacional de Pesquisas da Amazônia, dirigindo-o até 30 de outubro de 1955, juntamente com a Sra. Doris de Queiroz Carvalho, Bibliotecária; Renato Pereira de Carvalho para Chefe da Seção de Pessoal; e Carlos Flores Junior para Chefe da Seção de Material.

A sessão de instalação teve lugar no dia 27 de julho de 1954 , no auditório da Associação Comercial do Amazonas, sob a presidência do Dr. Arthur Cézar Ferreira Reis, então Superintendente do Plano de Valorização Econômica da Amazônia (S.P.V.E.A.), às dezesseis horas, estando presentes o Sr. Moisés Sabbá, Presidente da Associação Comercial do Amazonas, autoridades e muitas pessoas interessadas na programação do INPA.

As primeiras contribuições financeiras com que deveria contar o INPA, vieram das dotações reduzidíssimas do Conselho Nacional de Pesquisas (CrS $5.150 .000,00)$ e do convênio com a S.P.V.E.A., assinado a 30 de setembro, da ordem de CrS 2.850.000,00. O pessoal especializado convidado a prestar serviços foi selecionado entre professores de várias disciplinas, inclusive especialistas em assuntos amazônicos. Em 1955 começou a funcionar a Biblioteca inaugurada a 9 de novembro de 1954, já com algumas obras raras adquiridas com us recursos previstos.

Entre outras atividades iniciadas nesse ano figuram as Tecnológicas, com as primeiras demarches para obter-se celulose e papel de todos os tipos de madeiras do Amazonas, pelo processo "Isogrand", no que foi ajudado pelo Governo do Estado. Nesse mesmo ano foi assinado o acordo com o Governo do Estado do Pará para a administração e a direção científica do Museu Goeldi. 
Para obter-se o funcionamento racional do INPA nas bases previstas, foi ele estruturado em seis divisões e estas em secções, cujos resultados foram sempre promissores, sendo muito deles publicados em forma de livros, folhetos e páginas, ou em revistas especializadas no Brasil e no estrangeiro.

Desde aí o INPA passa a merecer o respeito e a consideração dos organismos nacionais e internacionais e a contar com recursos humanos recrutados em Universidades e Institutos de elevado conceito.

O INPA foi instalado primeiramente numa casa da praça da Saudade, extensão da rua de Simão Bolivar, alugada para a implantação dos serviços burocráticos e diretoria. Também no décimo andar do edifício IAPETEC ficaram instalados alguns serviços, inclusive Biblioteca, Botânica, Fotografia, etc. Em julho de 1956 assumiu a direção do INPA o terceiro diretor, Dr. Arthur Cézar Ferreira Reis, das mãos do Dr. Tito Arcoverde Cavalcanti, que renunciára e estava substituindo o professor Olímpio da Fonseca. O Dr. Arthur Reis estruturou o INPA em duas divisões apenas, a fim de ampliar os programas de pesquisas.

Nessa altura o INPA contava com dotações de CrS 22.000.000,00 e CrS $30.000 .000,00$, oriundas, respectivamente, do CNPq e da S.P.V.E.A. Nesse ano o acervo bibliotecário havia aumentado de 1.419 volumes para 6.907, especialmente em assuntos amazônicos e também foi adquirida a preciosa biblioteca do jornalista Frederico Barata. Ainda o INPA funcionava no edifício de propriedade da Beneficente PortugueSs à rua Guilherme Moreira n. ${ }^{\circ} 116$, onde foi reinaugurada a 12 de juIho. Os laboratórios foram inaugurados a 26 de julho de 1957.

Um dos objetivos principais do INPA foi a manutenção de Reservas Florestais implantadas na área municipal de Manaus, que possibilitassem não somente a preservação de espécies vegetais como facilitasse o estudo das mesmas. Para isso foi criada a Reserva Florestal Adolfo Ducke cuja demarcação foi efetuada em virtude da Ordem de Serviço n. 129/58, de 22 de abril. Em 1960 começou a funcionar o Laboratório-Piloto adquirido dois anos antes.

A 5 de outubro de 1959 foi nomeado Diretor do INPA o Dr. Djâlma da Cunha Batista, por ato do professor João Cardoso, Presidente do CNPq, em substituição ao Dr. Tito Arcoverde de Albuquerque Cavalcanti. Na gestão do Dr. Djalma Batista foi dado o maior impulso às pesquisas de campo e publicações desses resultados, na série denominada Cadernos da Amazônia. O INPA ativou a sua penetração na Amazônia, já agora com três divisões e vários setores, atraindo mais técnicos estrangeiros, consolidando a sua reputação e aumentando o número de estudos relativos aos problemas da Amazônia.

Durante todo esse período de atividade do INPA em prol da valorização da Amazônia, o Museu Emílio Goeldi manteve uma linha de trabalho que honra o nome do patrono. Numerosas foram as pesquisas realizadas e os trabalhos publicados, internacionalmente conhecidos. Aquela repartição anexa ao INPA deu os mártires da ciência, sacrificados no cumprimento de suas obrigações. 
No dia 31 de março de 1969 assumiu a direção do INPA o Dr. Paulo de Almeida Machado em substituição ao Dr. Octávio Hamilton Botelho Mourão, que dirigiu o Instituto de 20 de março de 1968 até 26 de março de 1969, após haver deịxacio o cargo o Dr. Dalcy de Oliveira Albuquerque. O Dr. Paulo de Almeida Machado deu início às primeiras demarches para a reorganização do INPA em termos de capacidade atuante na área amazônica, formulando pedidos ao Vice-Presidente do CNPq., então o Professor Heitor Grilo, para a importação de material científico, e início da construção da Sede nova, formulação e orçamentação de programas, planejamento de construção de barco-laboratório, aquisiçăo e reforma da oficina flutuante de manutenção, elaboração de projetos de Convênios.

Já em 1971, janeiro, prosseguiam as obras de construções dos pavilhões para laboratórios de Fatores Ambientais, Depósitos de Inflamáveis, Pesquisas Bio-Médicas, Pesquisas Fitoquímicas, Administração, pavimentação, sinalização e ajardinamento na área cedida pelo Estado do Amazonas, na Estrada do Aleixo, esquina da Avenida Perimetral. Iniciada em 1971 a construção do segundo barco-laboratório, recebendo os dois, respectivamente os nomes "Marupiara" e "Pyatä". Para ativar ainda mais os trabalhos do INPA, o Dr. Paulo Machado viajou ao exterior a fim de contactuar com Universidades e Institutos Tecnológicos, conseguindo maior intercâmbio com o INPA.

Hoje o INPA conta com 37 pavilhões e bangalôs modernos para pesquisadores residentes e em trânsito, afora outros melhoramentos materiais e técnicos que transformaram o INPA numa já hoje conhecida internacionalmente CIDADE DA CIENCIA.

O INPA cumpre deste modo a sua maior finalidade que é valorizar a Amazônia em termos de atuação Científica, afinando-se pelo programa nacional implantado pela REVOLUÇÃO BRASILEIRA. 